\title{
Grevasse patterns at the onset to Ice Stream B, West Antarctica
}

\author{
S. F. Prige, ${ }^{*}$ I. M. Whillans \\ Byrd Polar Research Center and Department of Geological Sciences, The Ohio State University, 1090 Carmack Road, \\ Columbus, Ohio 43210-1002, U.S.A
}

\begin{abstract}
Sequential satellite imagery and modeling are used to investigate crevasse patterns at the head of Ice Stream B tributary Blb. The crevasses, informally called the "chromosomes", form at the upstream limit to Blb's northern shear margin and chaotic crevasse zone. We find that the onset to crevasse formation, and by inference the onset to streaming flow, has migrated upstream over time at a mean rate of $230(16) \mathrm{m} \mathrm{a}^{-1}$. A possible cause for that migration is changes in net basal friction due to changes in basal water production rate and storage.
\end{abstract}

\section{INTRODUGTION}

Ice Stream B is changing over time. The mouth of the ice stream is known to be slowing and widening (Stephenson and Bindschadler, 1988; Bindschadler and Vornberger, 1998). A similar reduction in speed and widening of the ice stream has been observed for the upper portion of tributary B2 (Hulbe and Whillans, 1997; Hamilton and others, 1998; Harrison and others, 1998). Neither the cause nor the future course of these changes is known with confidence. As a contribution to describing changes along the ice stream, we report on changes at the head of one of the tributaries to Ice Stream B (Fig. 1).

This study focuses on a special group of crevasses informally called the "chromosomes". It was discovered by Vornberger and Whillans (1986) and described in detail by Merry and Whillans (1993). The name refers to the unusual crevasse shapes, which bear resemblance to pairs of separating chromosomes (Fig. 2). The group of crevasses is located at the upstream end of the northernmost (glacier-right) shear margin to the Blb tributary of Ice Stream B. The manifestation of a heavily crevassed margin suggests that the area is very near the onset of ice-stream flow. Force-budget calculations indicate that ice speed and lateral drag increase in the along-flow direction while driving stress and basal drag decrease (Appendix and Fig. 8, shown later; see also Whillans and Van der Veen, 1997). Similar combinations of flow characteristics have been used to define ice-stream flow vs inland-style flow (Bentley, 1987; Bindschadler and others, 2000). Ice thickness and surface elevation at this site have been measured by radio-echo sounding (Retzlaff and others, 1993). Surface velocity measurements are obtained here by tracking of persistent features in repeat satellite imagery. Our objective is to describe the strain-rate and stress pattern in the region, model crevasse development and evolution, and explain the observed patterns of crevasses.

* Present address: SAIC General Sciences Corporation, 4600 Powder Mill Road, Beltsville, Maryland 207052675, U.S.A.

\section{GREVASSE GROUPS}

Crevasses within the chromosomes form distinct groups, as shown in Figure 3. The simplest examples are in group I. Crevasses forming chromosomes intersect with one another at a "node" (Fig. 2). Groups II and III contain crevasses similar to those in group I, but the curvature of the crevasses evolves from convex upstream to convex downstream. Faint sets of crevasses are also observed within the more developed crevasses of groups I and II. Relatively short sets of chromosomes, truncated by longer crevasses, are observed within group III.

The boundary between the ice stream and the interstream ridge includes nodes and, closer to the ridge, crevasses diagonal to ice-stream motion. Downstream these evolve

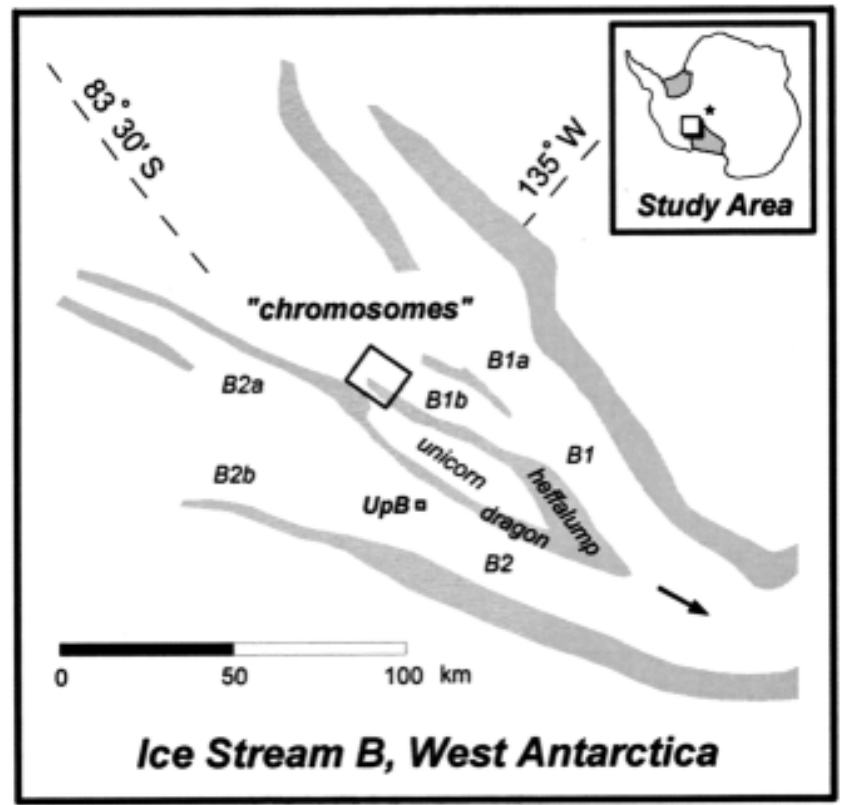

Fig. 1. Location of the study region. The small box outlines the study area (Fig. 2). Shaded regions are ice-stream shear margin boundaries from Shabtaie and Bentley (1987). The black arrow indicates the mean flow direction. 


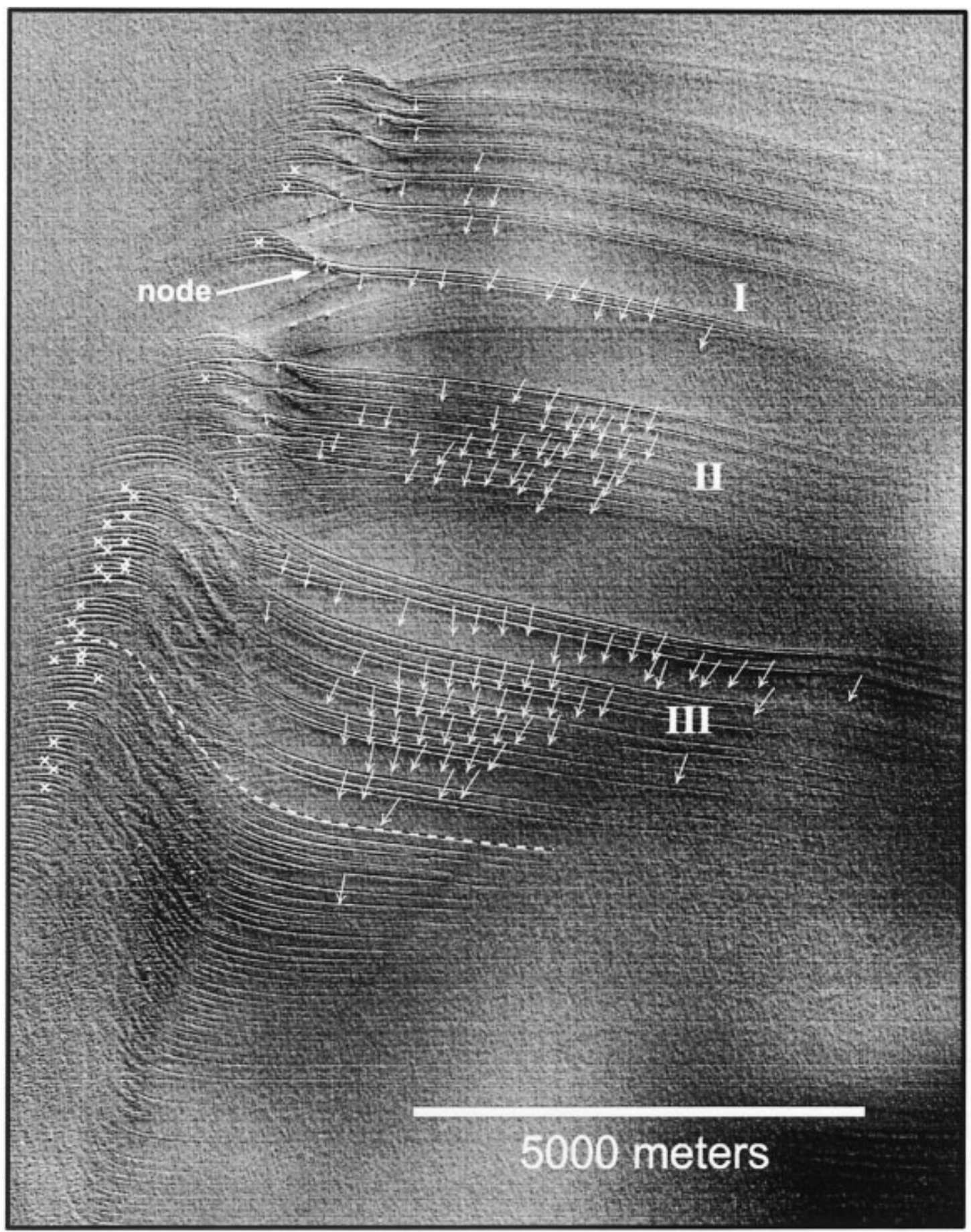

Fig. 2. SPOT HRV image of the study area. The white arrows are feature displacements over $\sim 4$ year time period. Crosses mark feature matches of near zero displacement outboard of the shear margin (the southern edge of the Unicorn). Roman numerals label the groups of crevasses discussed in the text. The dashed line marks the approximate beginning of the chaotic zone that develops downstream into the "heffalump" shear margin (image ID: 10905699312131619481P, (C) SPOT Image Corporation).

into a chaotic zone and outboard arcuate crevasses, respectively. The outboard arcuate crevasses are like those at other ice-stream margins and those modeled by Vornberger and Whillans (1990). The chaotic zone (rough-textured ice due to densely intersecting crevasses and drift mounds) that develops downstream of group III continues on to become the "heffalump" shear margin described by Merry and Whillans (1993).

\section{MOTION DETERMINATION}

Common surface features (i.e. crevasses and drift mounds) in a pair of spatially overlapping, temporally separated Système probatoire pour l'observation de la terre (SPOT) high resolution visible (HRV) images are tracked over a time interval of approximately 4 years (images acquired on 14 December 1989 and 13 December 1993). The method is similar to that developed by Bindschadler and Scambos (1991) and applied in other studies (Lucchitta and others, 1993, 1994, 1995; Bindschadler and others, 1994, 1996; Whillans and Tseng, 1995; Frezotti and others, 1998). Details on the feature-matching algorithm, a test of matching-derived velocities against independent measurements, and the quality assessment of matches can be found in Whillans and Tseng (1995).

Uncertainties in the geolocation of images result in false, systematic displacements, and require a more precise image co-registration. There are no rock outcrops in the region to 


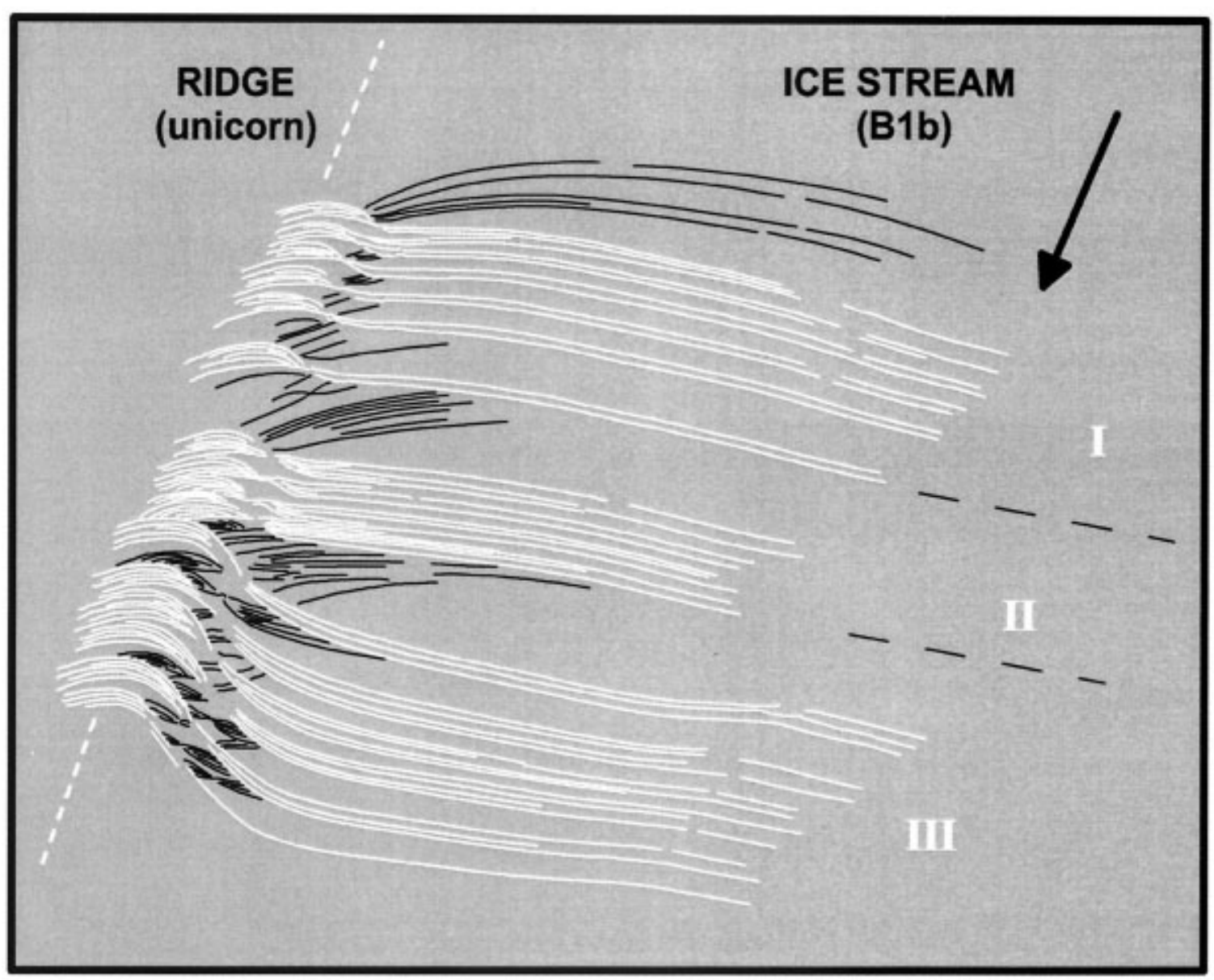

Fig. 3. Tracing of crevasses in Figure 2. I-III refer to three distinct groups of chromosomes (white traces). Faint crevasses are observed in group I and between groups I and II (black traces). Connecting crevasses and truncated chromosome packets are observed downstream of group II and within group III (black traces). The dashed white line marks the boundary between the ice stream and the interstream ridge (approximately connecting the zero-flow crossess in Fig. 2). The black arrow indicates the mean flow direction.

use for this purpose. However, surface-based measurements of ice motion in part of the region (the "unicorn", shown in Figs 1 and 3) are known to be $<3 \mathrm{~m} \mathrm{a}^{-1}$ (Whillans and Van der Veen, 1993). Over the time interval between the two images this estimated ice motion is less than a single $10 \mathrm{~m} \times 10 \mathrm{~m}$ pixel. Thus, this ice is nearly stagnant and features there can be used for image co-registration. Thirty-five common features were used to approximately co-register the two images. Thirty of these features are among the outboard crevasses shown in Figure 2, and five more are in a corresponding outboard position for the "dragon" (a shear margin farther north). No rotation correction was required to the orientations provided by SPOT image in order to achieve an accurate co-registration. The mean displacement of the 35 co-registration points is subtracted from feature-tracking displacements to remove most of the geolocation bias.

The residual co-registration bias leads to uncertainties in the measured components of velocity. The root-mean-square variation among the 35 co-registration points is $25 \mathrm{~m}$. This leads to an uncertainty in components of absolute velocity of $6.3 \mathrm{~m} \mathrm{a}^{-1}$. Relative velocities are more precise, being ultimately limited by the image pixel dimensions $(10 \mathrm{~m})$ and the time interval between images (3.998 a). The root-meansquare uncertainty in relative velocity components is $\left(10^{2} \mathrm{~m}^{2}+10^{2} \mathrm{~m}^{2}\right)^{1 / 2} / 3.998 \mathrm{a}=3.5 \mathrm{~m} \mathrm{a}^{-1}$.

Speeds into the head of tributary Blb are about $60 \mathrm{~m} \mathrm{a}^{-1}$ and increase to $80 \mathrm{~m} \mathrm{a}^{-1} 5 \mathrm{~km}$ downstream. Such speeds are typical for the heads of the ice streams (Whillans and Van der Veen, 1993; Price and Whillans, 1998; Joughin and others,
1999). Ice flow in the chromosomes region is likely dominated by motion at the glacier bed (Price, 1998).

\section{MODELING GREVASSE SHAPE}

Following conventional views on crevasse formation, crevasses are taken to form perpendicular to the principal extending strain rate, where that strain rate is sufficiently large (Nye, 1959; Meier and others, 1974; Raymond, 1980; Vornberger and Whillans, 1990; Vaughan, 1993). In this region, crevasses are observed to begin opening where displacement determinations find the principal extending strain rate to be about $0.003 \mathrm{a}^{-1}$. Over time, a crevasse may rotate according to differential velocity along its length. These two principles have been combined to successfully model other crevasse shapes on Ice Stream B (Vornberger and Whillans, 1990).

Merry and Whillans (1993) advanced a conceptual model to explain the nodes observed in the chromosomes region (see Merry and Whillans, 1993, fig. 3). Relatively newer crevasses intersect relatively older, more deformed crevasses at a common point of intersection, forming a node. For any chromosome-shaped set of crevasses, the oldest crevasse on the interstream ridge is that farthest upstream. Its temporal counterpart within the ice stream is the farthest downstream. While the nodes appear to be weak sites within the ice that encourage crevasse formation, their origin is unknown. As such, they are not included in the formulation of the present model.

We model the velocity field using polynomial expres- 
sions fit to the measured components of velocity shown in Figure 2. For each group of crevasses (I-III), the extent of velocity measurements defines the two-dimensional model domain. The $x$ and $y$ axes are aligned along- and acrossflow, respectively, and the origin is at the point of zero horizontal motion, where the crevasse trace intersects with the interstream ridge. A good representation of the measured velocity profiles is achieved with a first-order polynomial in the along-flow direction and a fourth-order polynomial in the across-flow direction. A fourth-order polynomial provides good approximations to across-flow velocity profiles elsewhere on Ice Stream B (Whillans and others, 1987). Those authors found that the along-flow component of velocity varied across-flow as a constant, times the distance from the ice-stream center line raised to the fourth power. In the present case, the position of the center line is not well known, so a polynomial containing all terms is used. A fourth-order relation also describes lateral drag resisting a significant fraction of the ice-stream motion. Approximately $60 \%$ of the resistance to motion in the chromosomes region is due to lateral drag (see Appendix), so the use of a fourth-order relation is valid. Figure 4 shows the measured velocities and the polynomial fits to those velocities. The polynomial representations of the velocities agree with discrete measurements to within the range of measurement uncertainties (see below) and are not expected to introduce any further uncertainties.

The strain-rate field for each crevasse group is calculated from the first derivative of the along- and across-flow polynomials (Fig. 4). The modeled crevasses are assumed to form where the principal extending strain rate is $\geq 0.003 \mathrm{a}^{-1}$ and to grow instantaneously along their length, perpendicular to the principal extending strain rate. Crevasses are allowed to grow to the limits of the model domain. Because the model does not include the role of nodes, modeled crevasses intersect with the interstream ridge instead of slightly inboard of the ridge. A modeled crevasse trace for group III is shown in Figure 5.

The main features of the modeled crevasse are that the trace of the crevasse evolves from convex upstream to convex downstream. The change in shape is most pronounced in the region within about $3 \mathrm{~km}$ from the interstream-ridge/icestream boundary. The modeled evolution of crevasse shape closely resembles crevasse shapes observed in the imagery (Fig. 2).

\section{MATGHING MODEL TO OBSERVATION}

The match between modeled and observed crevasses is used to assign dates and positions of formation to select crevasses in groups I-III. Crevasse age and nascent shape are mapped in Figure 6. Age vs nascent position along the transect A- $\mathrm{A}^{\prime}$ in Figure 6 is shown in Figure 7. Progressively younger crevasses have formed farther upstream over time. This means that the sites of crevasse formation have migrated upstream over time. The solid line in Figure 7 is a linear fit to these values. It indicates a mean migration rate of $230 \mathrm{~m} \mathrm{a}^{-1}$.

\section{Uncertainties in crevasse age and nascent site}

Uncertainties in the estimated age of the crevasses are due to uncertainties in the measured strain rates and to the possibility that strain rates have changed over time. Based on propagation of measurement uncertainties, the uncertainty
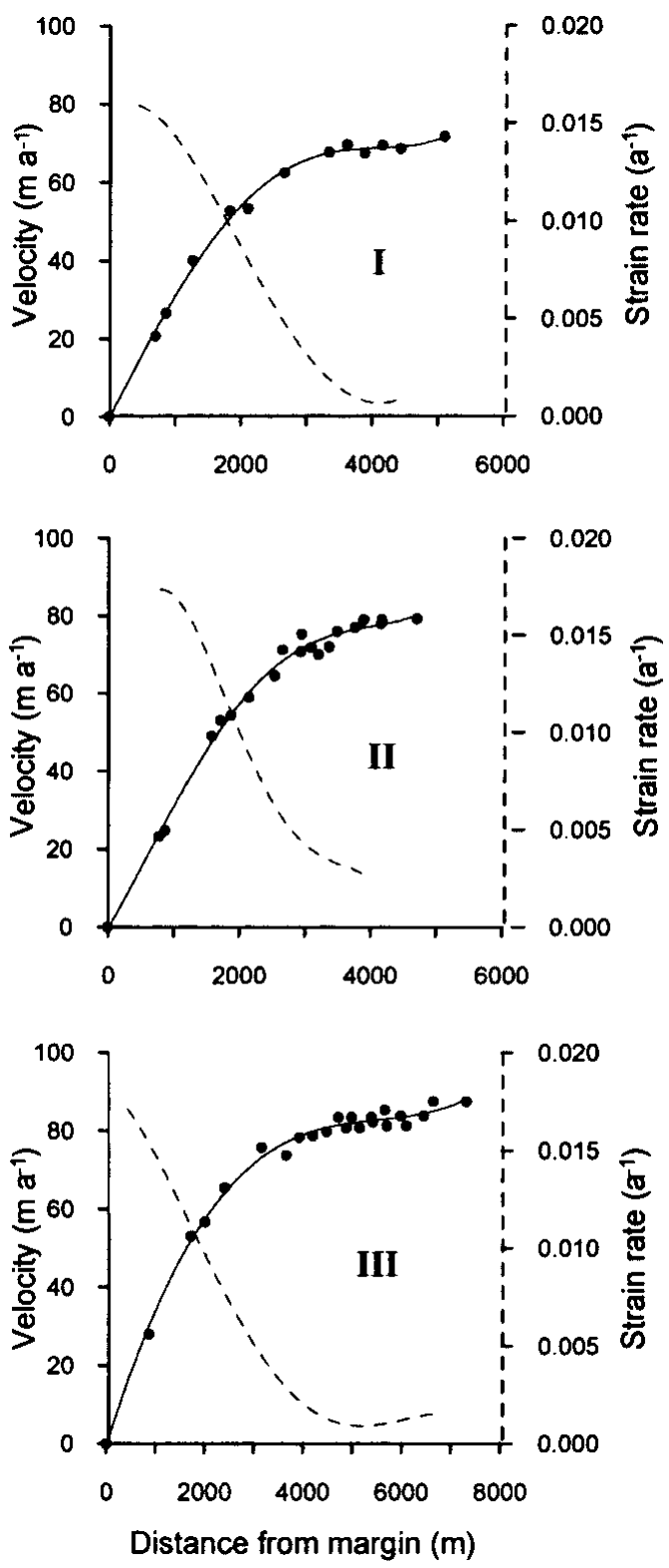

Fig. 4. Along-flow component of velocity measured within crevasse groups I-III (filled circles), plotted with distance from the ice-stream margin (white line in Fig. 3). Fourthorder polynomial fits to the velocities (solid curves and axes) and shear strain rates derived from them (dashed curves and axes) are also shown. The $R^{2}$ values for all fits are $\geq 0.99$.

in shear strain rates calculated from neighboring feature matches is $\leq 0.003 \mathrm{a}^{-1}$. The uncertainty in along-flow stretching rates is $\sim 0.001 \mathrm{a}^{-1}$. The small difference derives from the fact that the along-flow stretching rate is less variable in the across-flow direction than is the across-flow shearing rate. The primary region of interest for crevasse modeling is within $3 \mathrm{~km}$ of the interstream ridge, where the deformation is concentrated. Within this zone, the uncertainty in strain rates results in an age uncertainty of ( $\leq 5$ years for the modeled crevasses. Propagating these uncertainties leads to an uncertainty of $16 \mathrm{~m} \mathrm{a}^{-1}$ in the mean migration rate of nascent sites.

The sites of crevasse initiation appear to have migrated upstream over time, implying that stretching rates and ice speed in the region have increased over time. For any fixed geographic location, the mean velocity over time would then be slightly less than the present-day velocities used in the modeling. This effect would lead to a slight increase in 


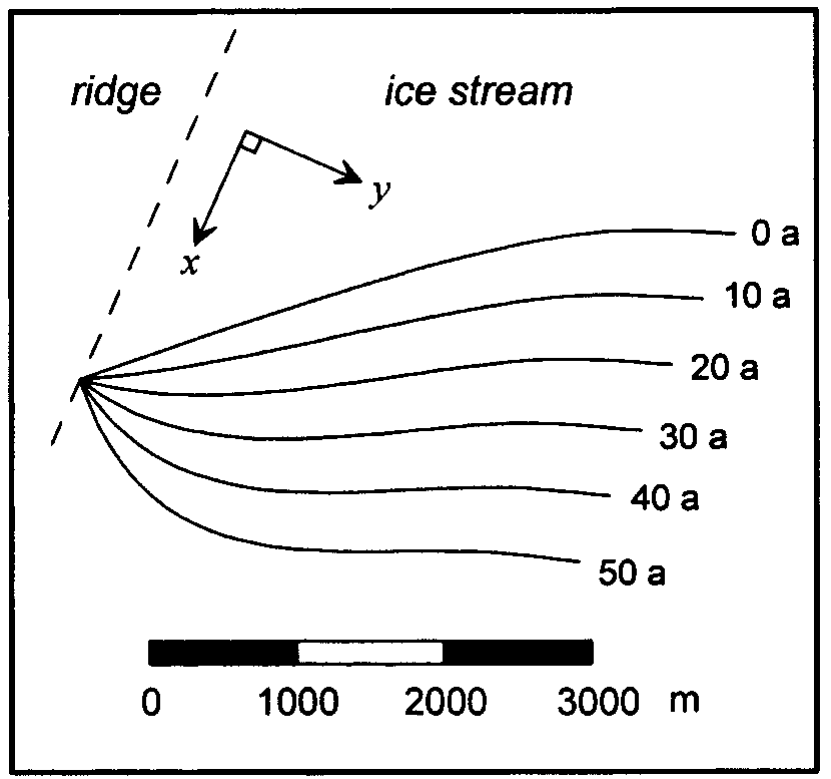

Fig. 5. Modeled crevasse shapes for group III at 10 year time intervals. Ice flow is in the x direction. The black dashed line is equivalent to the white dashed line in Figure 3.

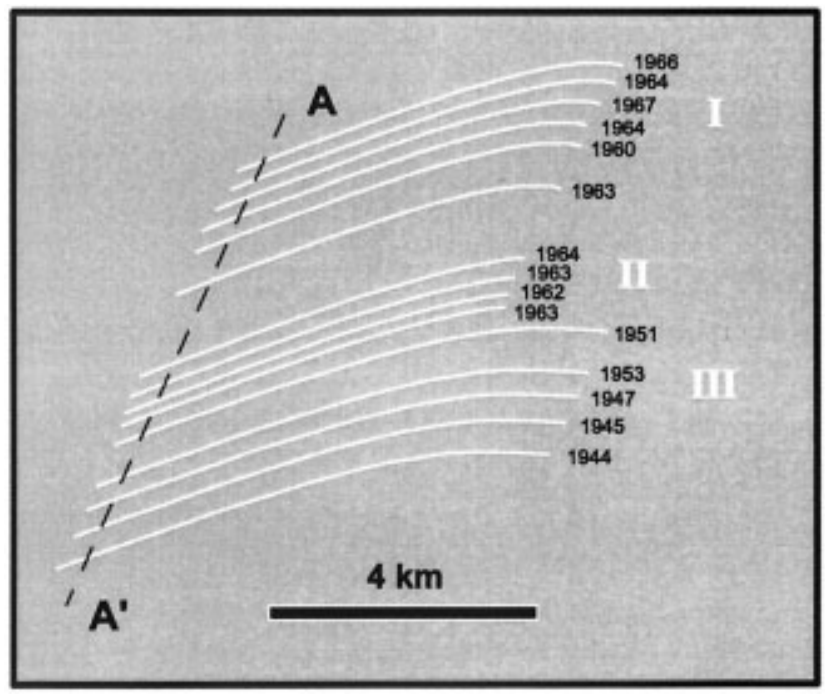

Fig. 6. Modeled age, nascent shape and nascent position of select crevasses within crevasse groups I-III. The black dashed line is equivalent to the white dashed line in Figure 3.

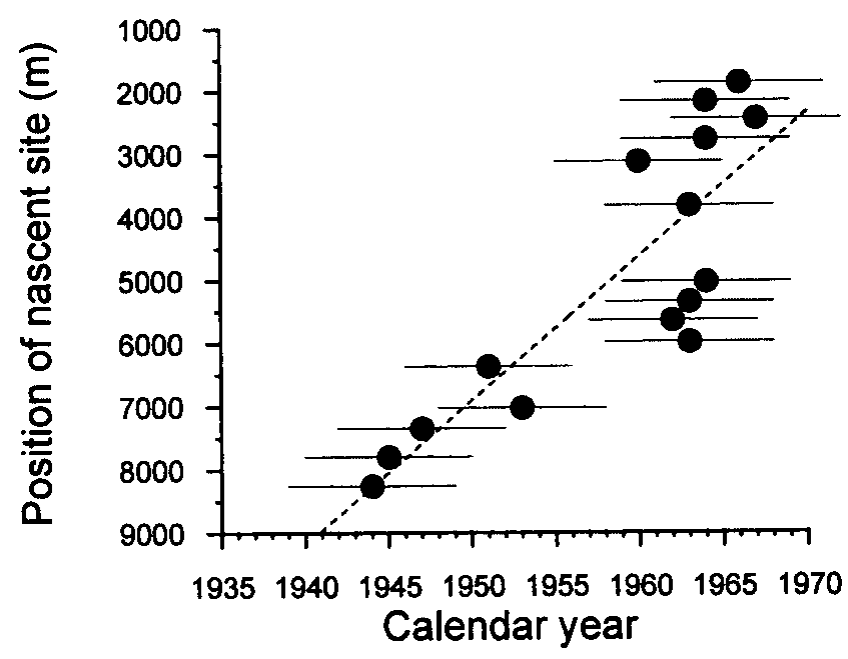

Fig. 7. Position of nascent crevasse sites over time along line $A-A^{\prime}$ in Figure 6. The most upstream crevasses in Figure 2 are at $\sim 1500 \mathrm{~m}$ on the vertical axis, and the most downstream are at $\sim 8500$ m. $1 \sigma$ error bars are shown. the ages of crevasses presented here. The calculated migration rate would be relatively unaffected.

\section{GAUSE OF GHANGES IN ONSET LOGATION}

The site of tension large enough to form crevasses appears to have migrated upstream over time. This implies an upstream migration of the ice-stream onset. Thus, stretching rates and glacier speed at a geographically fixed site have increased. The most likely explanation for these changes is an increase over time in the rate of basal slip near the onset site.

The fast speed of ice streams is enabled by basal lubrication that favors rapid motion at the bed. By extension, the beginning of ice-stream flow must be associated with an along-flow increase in lubrication. The amount of lubrication is linked with some combination of water production rate, water collection at the bed and bed roughness. Perhaps one or more of these quantities has changed over time at the onset, resulting in faster ice speeds and a subsequent upstream migration of the ice-stream onset.

The rate of meltwater production is linked to the rate of work done by the moving ice stream, expressed as the product of speed and driving stress. The driving stress is about twice as large among group II and III crevasses as elsewhere (Fig. 8). Ice velocity has been measured $12 \mathrm{~km}$ downstream of the chromosomes (station 13 of Whillans and Van der Veen (1993)), within the chromosomes, and is estimated for upstream sites according to the along-flow velocity gradient measured here. The product of driving stress and speed (which may be discerned from the curves in Figure 8) has a maximum near groups II and III. A small change in speed or driving stress could lead to a positive feedback in heat production, which could further alter ice speed. A feedback between basal melting and ice speed could be responsible for the current location of the onset and for changes in the onset site over time.

Changes in the volume of subglacial water are a second possible cause for the implied time changes at the crevasse initiation site. The amount of subglacial water depends on water production and on the subglacial hydrologic potential gradient: the smaller the gradient, the more probable subglacial ponding. The gradient is calculated from measurements of ice thickness and surface elevation (Retzlaff and others, 1993), neglecting spatial variations in effective pressure. Water-flow trajectories from upstream converge towards the head of Ice Stream Blb $(x=y=-4.5$ in fig. 1 of Alley and others (1994)). Furthermore, there is a reverse basal gradient ( $x \approx 15-25 \mathrm{~km}$ in Fig. 8 ) that is an order of magnitude larger than the surface slope, making a favorable setting for a subglacial lake (and the elimination of subglacial friction). Small changes in the surface elevation profile in the vicinity of the lake would cause changes in lake area. An increase in the lake area would lubricate more of the bed and result in a speed increase in the chromosomes region. The increase in speed would stretch and thin the ice upstream, thereby reducing the surface slope and providing a positive feedback on lake size. Time-changes in the area of the proposed lake could be the reason for the observed iceflow changes in the chromosomes region.

If a subglacial lake exists, it might be identified by geophysical studies. Bentley and others (1998) used airborne radio-echo sounding to produce maps of basal-reflection strength beneath the downstream portions of Ice Streams 


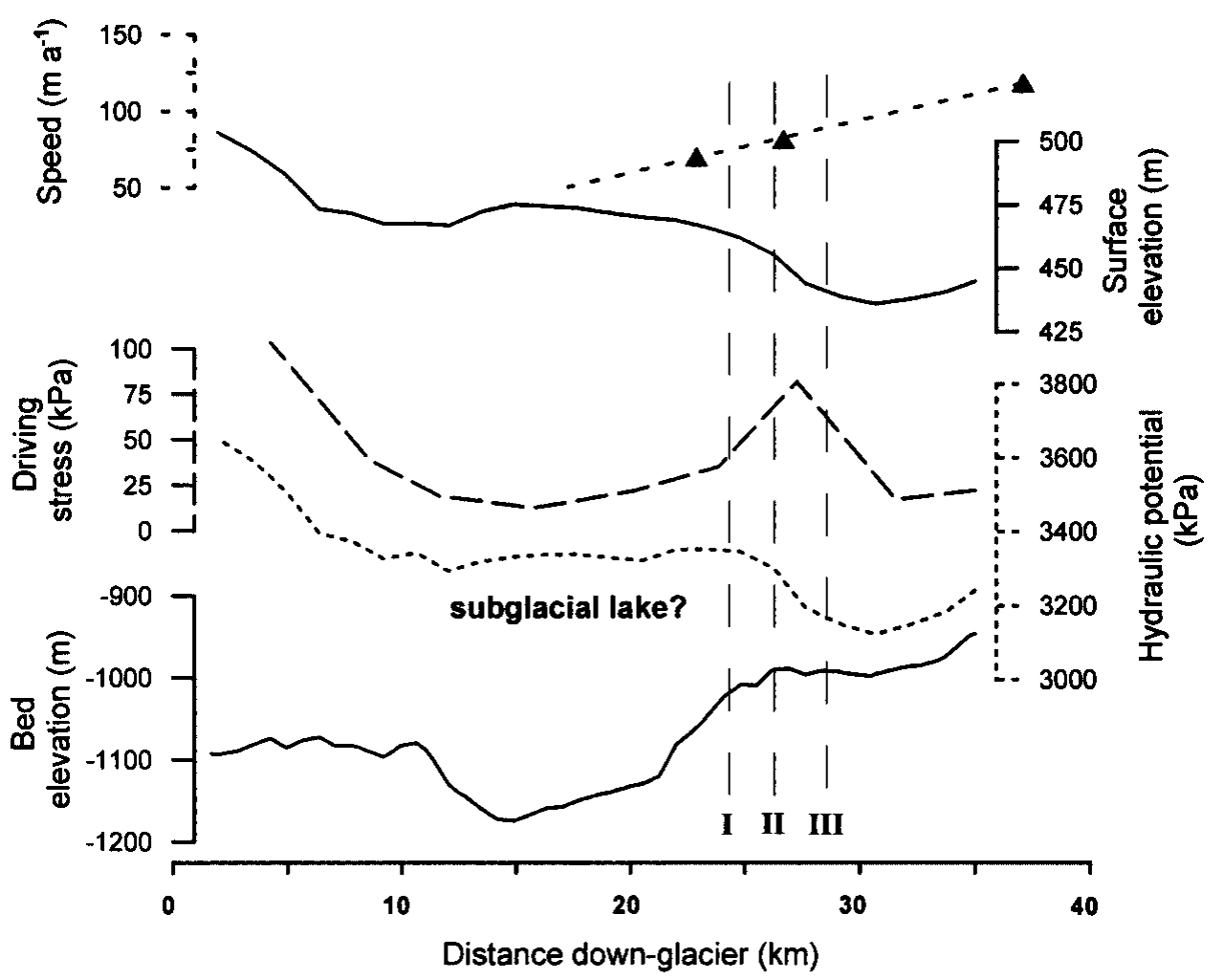

Fig. 8: Surface speed (upper dashed line), surface elevation (upper solid line), driving stress averaged over $\sim 10 \mathrm{~km}$ (long-dashed line, middle), hydraulic potential (short-dashed line, middle) and basal elevation (lower solid line) along a downstream transect that includes the chromosomes region. The locations of crevasse groups I-III are indicated by long, vertical dashes. Flow is from left to right. The triangles in the uppermost plot are velocity measurements within and downstream of the study area. The dashed black line is a linear fit to those data. The most downstream measurement (rightmost) is station 13 from Whillans and Van der Veen (1993).

$\mathrm{B}$ and $\mathrm{C}$. The reflection strength is used to delimit areas of the bed that are wet vs areas that are frozen. Similar analysis of the radio-echo sounding data from Retzlaff and others (1993) could be used to look for evidence of the proposed lake upstream from the chromosomes. Unfortunately, thick ice and signal scattering from surface and buried crevasses limits the sensitivity of the basal-reflection strength in these areas. Subglacial lakes on the scale of $\leq 10 \mathrm{~km}$ would not likely be observed through a similar analysis (personal communication from N. Lord, 1999).

A third possibility for the migration of the ice-stream onset is an along-flow change in bed roughness. The roughness change could be between igneous and sedimentary rock (e.g. Anandakrishnan and others, 1998; Bell and others, 1998), between different types of sedimentary rocks, or could involve the presence or absence of a soft, moldable, basal till. However, it seems unlikely that bed roughness could change over the short time-scales being considered (tens of years). This hypothesis is thus discarded.

\section{DEVELOPMENT OF GREVASSE PATTERNS}

There is a simple progression of crevasse types along-flow in the region. The presence of the nodes would seem to indicate that these are nucleation sites; from the nodes, crevasses grow toward the interstream ridge to make the outboard "hook-shaped" crevasses and also grow toward the ice stream, where their growth directions become more transverse to flow. Initially, all crevasses are convex upstream. Over time, shear strain rotates the crevasses out of alignment with the causative stress field and they become progressively more convex downstream. Our observations (Figs 2 and 3) indicate that after rotation of about $10^{\circ}$, new crevasses can form at the original, convex-upstream orientations.

Minor sets of chromosomes, truncated by longer crevasses, are observed in group III, close to the interstream ridge (Fig. 3). After the long crevasses are rotated downstream, short, connecting crevasses appear to form between them. Over time, these connecting crevasses are also rotated downstream, and new crevasses open up at the old orientations. The minor, truncated sets of chromosomes form in a manner similar to the longer chromosome sets but within a more limited area.

A "chaotic zone", like the one observed near the bottom of the image in Figure 2, is the product of continued development of the region most densely populated with crevasses. At this point, crevasses have undergone a net rotation of approximately $90^{\circ}$ and have been subjected to a shear strain rate of $0.010-0.015 \mathrm{a}^{-1}$ for approximately 50 years. A chaotic zone is then a suite of crevasses similar to the ones modeled here, but with so many superposed generations that specific crevasse histories are difficult to unravel.

The faint crevasses within groups I and II appear to be buried (Figs 2 and 3). This interpretation would suggest that they are older than more prominent crevasses nearby and possibly inactive. However, the faint crevasses are forming near the nascent sites for crevasse groups I and II, and their shape is similar to that modeled for very young crevasses (Fig. 5). These crevasses are likely the youngest observed in the imagery. Possibly they lack wide, sagging bridges, making them appear faint in the imagery. Our model predicts that the faint crevasses formed between approximately 1979 and 1989. Aerial photographs from 1983 show the same sets of faint crevasses, so they must have formed closer to 1979 in order to be wide enough for detection in the photos. 
A 1995 SPOT image shows no crevasses in addition to those seen in the 1983 aerial photos. If new crevasses have formed in the region they are not wide enough to be visible in the most recent SPOT image. Alternatively, there may have been a hiatus in crevasse formation between the time of the photos and the time of the recent images. A hiatus of similar length is observed to have taken place between the 1950s and the 1960s (Fig. 7).

\section{GONGLUSIONS}

Inland migration of the ice-stream onsets has been predicted or inferred in previous work, but never measured directly. Alley and Whillans (1991) and Bindschadler (1997) derived headward migration rates on the order of $500 \mathrm{~m} \mathrm{a}^{-1}$. That is comparable to our measured rate of $230 \mathrm{~m} \mathrm{a}^{-1}$. Interestingly, the retreat rate of the grounding line over the past 7500 years is of a similar scale (120 $\mathrm{m} \mathrm{a}^{-1}$; Conway and others, 1999). If the migration rate measured here persists, the onset to tributary Blb would reach the inland West Antarctic ice-sheet divide in approximately 1400 years.

The discovery of inland migration at an onset to Ice Stream B, together with the overall negative mass balance of Ice Stream B's catchment (Whillans and Bindschadler, 1988), indicates that changes in the West Antarctic ice streams occur at their most inland reaches. Changes on the ice streams are not limited to the grounding zone, but also involve the central portion of grounded ice, thereby having relevance to the long-term behavior of the ice sheet and global sea level.

The cause for the migration is not known, but it likely involves changes in the rate of production, or more likely the storage of subglacial water near the ice-stream onset. Subglacial water storage is related to the combination of reverse-sloping-bed topography and, more importantly, shallow surface slope. It is beyond the scope of the present work to speculate on the initial cause for the shallow surface slopes near the ice-stream onset (e.g. regional mass-balance changes, long-term ice-sheet thinning). However, it is noted that this geometry, once established, may lead to a positive feedback between subglacial water storage, inland onset migration and further shallowing of surface slopes upstream.

The present analysis of crevasse evolution suggests a kinematic model for the formation of an ice-stream chaotic zone within a developing shear margin. Crevasses form in a zone of shear, but rotation of crevasses out of alignment with the stress field leads to the formation of new crevasses. Over time, this process creates a region of densely intersecting crevasses that ultimately becomes the chaotic zone. The "heffalump" chaotic zone at the northern margin to Blb takes approximately 50 years to form over a distance of $3 \mathrm{~km}$. Once formed, it is maintained for the full length of the ice-stream tributary ( $180 \mathrm{~km}$; Merry and Whillans, 1993).

\section{ACKNOWLEDGEMENTS}

Suggestions from D. Dahl-Jensen and an anonymous reviewer helped to improve the manuscript. The authors also wish to thank C. Hulbe and R. Bindschadler for many helpful comments. Research was supported by the U.S. National Science Foundation (grant No. OPP-9316509). This is Byrd Polar Research Center contribution No. 1190.

\section{REFERENCES}

Alley, R. B. and I. M. Whillans. 1991. Changes in the West Antarctic ice sheet. Science, 254(5034), 959-963.

Alley, R. B., S. Anandakrishnan, C. R. Bentley and N. Lord. 1994. A waterpiracy hypothesis for the stagnation of Ice Stream C, Antarctica. Ann. Glaciol., 20, 187-194.

Anandakrishnan, S., D. D. Blankenship, R. B. Alley and P. L. Stoffa. 1998. Influence of subglacial geology on the position of a West Antarctic ice stream from seismic observations. Nature, 394(6688), 62-65.

Bell, R. E. and 6 others. 1998. Influence of subglacial geology on the onset of a West Antarctic ice stream from aerogeophysical observations. Nature, 394(6688), 58-62.

Bentley, C. R. 1987. Antarctic ice streams: a review. F. Geophys. Res., 92(B9), 8843-8858.

Bentley, C. R., N. Lord and C. Liu. 1998. Radar reflections reveal a wet bed beneath stagnant Ice Stream C and a frozen bed beneath ridge BC, West Antarctica. F. Glaciol., 44(146), 149-156.

Bindschadler, R. 1997. Actively surging West Antarctic ice streams and their response characteristics. Ann. Glaciol., 24, 409-414.

Bindschadler, R. A. and T. A. Scambos. 1991. Satellite-image-derived velocity field of an Antarctic ice stream. Science, 252(5003), 242-246.

Bindschadler, R. and P. Vornberger. 1998. Changes in the West Antarctic ice sheet since 1963 from declassified satellite photography. Science, 279(5351), 689-692.

Bindschadler, R. A., M. A. Fahnestock, P. Skvarca and T. A. Scambos. 1994. Surface-velocity field of the northern Larsen Ice Shelf, Antarctica. Ann. Glaciol., 20, 319-326.

Bindschadler, R., P. Vornberger, D. Blankenship, T. Scambos and R. Jacobel. 1996. Surface velocity and mass balance of Ice Streams D and E, West Antarctica. 7. Glaciol., 42(142), 461-475.

Bindschadler, R., X. Chen and P. Vornberger. 2000. The onset area of Ice Stream D, West Antarctica. 7. Glaciol., 46(152), 95-101.

Conway, H., B. L. Hall, G. H. Denton, A. M. Gades and E. D. Waddington. 1999. Past and future grounding-line retreat of the West Antarctic ice sheet. Science, 286(5438), 280-283.

Engelhardt, H., N. Humphrey, B. Kamb and M. Fahnestock. 1990. Physical conditions at the base of a fast moving Antarctic ice stream. Science, 248 (4951), 57-59.

Frezzotti, M., A. Capra and L. Vittuari. 1998. Comparison between glacier ice velocities inferred from GPS and sequential satellite images. Ann. Glaciol., 27, 54-60.

Hamilton, G. S., I. M. Whillans and P. J. Morgan. 1998. First point measurements of ice-sheet thickness change in Antarctica. Ann. Glaciol., 27, 125-129.

Harrison, W. D., K. A. Echelmeyer and C. F. Larsen. 1998. Measurement of temperature in a margin of Ice Stream B, Antarctica: implications for margin migration and lateral drag. F. Glaciol., 44(148), 615-624.

Hooke, R. LeB. 1998. Principles of glacier mechanics. Upper Saddle River, NJ, Prentice Hall.

Hulbe, G. L. and I. M. Whillans. 1997. Weak bands within Ice Stream B, West Antarctica. 7. Glaciol., 43(145), 377-386.

Joughin, I. and 7 others. 1999. Tributaries of West Antarctic ice streams revealed by RADARSAT interferometry. Science, 286(5438), 283-286.

Lucchitta, B. K., K. F. Mullins, A. L. Allison and J. G. Ferrigno. 1993. Antarctic glacier-tongue velocities from Landsat images: first results. Ann. Glaciol., 17, 356-366.

Lucchitta, B. K., K. F. Mullins, C. E. Smith and J. G. Ferrigno. 1994. Velocities of the Smith Glacier ice tongue and Dotson Ice Shelf, Walgreen Coast, Marie Byrd Land, West Antarctica. Ann. Glaciol., 20, 101-109.

Lucchitta, B. K., C. E. Rosanova and K. F. Mullins. 1995. Velocities of Pine Island Glacier, West Antarctica, from ERS-1 SAR images. Ann. Glaciol., 21, 277-283.

Meier, M. F., W. B. Kamb, C. R. Allen and R. P. Sharp. 1974. Flow of Blue Glacier, Olympic Mountains, Washington, U.S.A. f. Glaciol., 13(68), 187-212.

Merry, C. J. and I. M. Whillans. 1993. Ice-flow features on Ice Stream B, Antarctica, revealed by SPOT HRV imagery. f. Glaciol., 39(133), 515-527.

Nye, J. F. 1959. A method of determining the strain-rate tensor at the surface of a glacier. 7. Glaciol., 3 (25), 409-419.

Price, S. F. 1998. Studies in the catchment and onset regions of Ice Stream B, West Antarctica. (M.Sc. thesis, Ohio State University.)

Price, S. F. and I. M. Whillans. 1998. Delineation of a catchment boundary using velocity and elevation measurements. Ann. Glaciol., 27, 140-144.

Raymond, C. F. 1980. Temperate valley glaciers. In Colbeck, S. C., ed. Dynamics of snow and ice masses. New York, Academic Press, 79-139.

Retzlaff, R., N. Lord and C. R. Bentley. 1993. Airborne-radar studies: Ice Streams A, B and C, West Antarctica. F. Glaciol., 39(133), 495-506.

Shabtaie, S. and C. R. Bentley. 1987. West Antarctic ice streams draining into the Ross Ice Shelf: configuration and mass balance. 7. Geophys. Res., 92(B2), 1311-1336. (Erratum: f. Geophys. Res., 1987, 92(B9), 9451.) 
Stephenson, S. N. and R. A. Bindschadler. 1988. Observed velocity fluctuations on a major Antarctic ice stream. Nature, 334(6184), 695-697.

Vaughan, D. G. 1993. Relating the occurrence of crevasses to surface strain rates. F. Glaciol., 39(132), 255-266.

Vornberger, P. L. and I. M. Whillans. 1986. Surface features of Ice Stream B, Marie Byrd Land, West Antarctica. Ann. Glaciol., 8, 168-170.

Vornberger, P. L. and I. M. Whillans. 1990. Crevasse deformation and examples from Ice Stream B, Antarctica. 7. Glaciol., 36(122), 3-10.

Whillans, I. M. and R. A. Bindschadler. 1988. Mass balance of Ice Stream B, West Antarctica. Ann. Glaciol., 11, 187-193.

Whillans, I. M. and Y.-H. Tseng. 1995. Automatic tracking of crevasses on satellite images. Cold Reg. Sci. Technol., 23(2), 201-214.

Whillans, I. M. and C. J. van der Veen. 1993. New and improved determinations of velocity of Ice Streams B and C, West Antarctica. 7. Glaciol., 39(133), 483-490.

Whillans, I. M. and C. J. van der Veen. 1997. The role of lateral drag in the dynamics of Ice Stream B, Antarctica. f. Glaciol., 43(144), 231-237.

Whillans, I. M., J. Bolzan and S. Shabtaie. 1987. Velocity of Ice Streams B and C, Antarctica. 7. Geophys. Res., 92(B9), 8895-8902.

\section{APPENDIX}

\section{Force balance at the head of Ice Stream B1b}

The role of lateral shear stress in resisting the ice motion can be estimated according to the large-scale balance of forces, following the method of Whillans and Van der Veen (1997). The balance of forces acting on a block of ice with length $L$, width $W$ and mean thickness $H$ is

$$
\begin{aligned}
L W \tau_{\mathrm{d} x} & -L W \tau_{\mathrm{b} x}-L H R_{x y} \\
& -W H R_{x x(\mathrm{up})}+W H R_{x x(\text { down })}=0
\end{aligned}
$$

in a Cartesian coordinate system. The $x$ and $y$ axes are in the horizontal plane and are oriented along- and acrossflow, respectively. $L$ is parallel to the ice-flow direction and $W$ is equal to the half-width of the ice stream. Dividing Equation $(\mathrm{Al})$ by the area, $L W$, gives the balance equation in terms of stresses,

$$
\tau_{\mathrm{d} x}-\tau_{\mathrm{b} x}-\left(\frac{H}{W} R_{x y}\right)-\left(\frac{H}{L} R_{x x(\text { up })}\right)+\left(\frac{H}{L} R_{x x(\text { down })}\right)=0 .
$$

The first term on the left in Equation (A2) is the driving stress, given by the familiar relation $\tau_{\mathrm{d} x}=\rho g H \sin \alpha$, where $\rho$ is the density of ice, $g$ is the acceleration due to gravity and $\alpha$ is the ice-sheet surface slope. Driving stress is balanced by basal drag (second term on the left in Equation (A2)), lateral drag (third term on the left in Equation (A2)), and longitudinal stresses pulling upstream and downstream (fourth and fifth terms on the left in Equation (A2), respectively). $R_{x y}$ and $R_{x x}$ are the depth-averaged shear and longitudinal resistive stresses, respectively. Longitudinal stresses are negligible when considering averages over long distances (e.g. Whillans and Van der Veen, 1993, 1997), as is done here. Neglecting the longitudinal terms leaves:

$$
\tau_{\mathrm{d} x}=\tau_{\mathrm{b} x}-\frac{H}{W} R_{x y} .
$$

Driving stress is balanced by drag at the glacier bed and by lateral shear stress.

Shear stress is computed using a simplification of the inverse flow law for glacier ice,

$$
R_{x y}=B\left[\frac{1}{2}\left|\frac{\partial u_{x}}{\partial y}\right|\right]^{\frac{1}{3}-1}\left(\frac{1}{2} \frac{\partial u_{x}}{\partial y}\right),
$$

where $u_{x}$ is the component of velocity parallel to ice flow. The last term on the right is the shear strain rate, in which gradients in the across-flow component of velocity are ignored because they are negligible in the study area. The shear strain rate is at least an order of magnitude larger than other strain rates in the region, and so is assumed to be approximately equal to the effective strain rate in Equation (A4) (term in square brackets). $B$ is the temperature-dependent rate factor (Hooke, 1998).

Lateral drag at the chromosomes site is calculated using data from several sources. Shear strain rates are taken from the feature-tracking displacements presented here. The rate factor is a depth-averaged value, calculated according to a temperature profile measured near the Upstream Bravo (UpB) camp on tributary B2 (Engelhardt and others, 1990). The half-width of tributary Blb $(W)$ is estimated from satellite imagery, and the mean thickness $(H)$ is taken from maps of Retzlaff and others (1993). The mean driving stress, lateral drag and basal drag are 39, 23 and $16 \mathrm{kPa}$, respectively, so lateral drag accounts for $60 \%$ of the resistance to flow. Between 10 and $20 \mathrm{~km}$ downstream of the chromosomes, the mean driving stress, lateral drag and basal drag are 12 , 12 and $0 \mathrm{kPa}$, respectively, so lateral drag accounts for $100 \%$ of the resistance to flow (Whillans and Van der Veen, 1997, table 1). The measurements indicate that within the chromosomes region, lateral drag is progressively replacing basal drag as the dominant control on ice motion. 